\title{
Approaching Stress and Performance in RSI: Proposal for Action to Take Back Control
}

\author{
Dora Murgu \\ ${ }^{1}$ Interprefy AG, Bellerivestrasse 11, CH-8008 Zürich, Switzerland \\ Dora.Murgueinterprefy.com
}

\begin{abstract}
The relationship between stress and performance and Remote Interpreting (RI)/Remote Simultaneous Interpreting (RSI) has been widely studied in academic, professional and corporate research during the past fifty years. Most of such research has attempted to correlate RI/RSI with changes in stress levels and performance, with little to no relevant results to suggest causality. While no significant clinical causality has been found between RI/RSI and stress, selfperceived stress during RI and especially RSI among practicing conference interpreters is consistently high and recent studies suggest a tendency on the in crease. Similar results have been observed with performance, which has been and is consistently self-assessed as poorer during RI/RSI by practicing interpreters compared to in-person interpreting, however no significant decrease in performance was observed by independent reviewers. Several scholars have suggested a correlation between such low self-perceived performance / high self-perceived stress and a lack of control which might result from being exposed to unknown factors during RI/RSI, prominently technological elements, the performance of which no longer relies on third parties but lies with the interpreters themselves. This paper is centered on the same hypothesis and suggests a proposal for action that interpreters can undertake to help regain control and thus improve their attitude toward RI/RSI.
\end{abstract}

Keywords: Remote simultaneous interpreting, performance, stress management, interpreter education, risk management, PMI.

"(remote interpreters) require different problem-solving and capacity management strategies in order to be better prepared to face new situations"

Andres Dörte \& Stefanie Falk

\section{$1 \quad$ Stress and Remote Interpreting in Literature}

The relationship between stress, performance and remote interpreting was first identified in the 70s in experiments conducted during several meetings held by UN organizations. They all resulted in interpreters complaining of an increase in stress levels. (Dörte \& Falk, 2009). The perception of increased stress has been consistently identified in subsequent studies performed by United Nations and European Institutions 
(Mouzourakis, 2006) with interpreters generally concluding that remote interpreting, as compared to on-site interpreting, causes higher levels of stress, fatigue and results in lower performance.

\section{The focus on RSI}

With the rise of remote simultaneous interpreting delivery platforms in the mid $2010 \mathrm{~s}$ and especially the hypergrowth of remote simultaneous interpreting assignments in 2020 as a result of the world pandemic, research has shifted from remote interpreting to remote simultaneous interpreting to reanalyze its impact on the health, wellbeing and performance of conference interpreters working remotely.

Studies conducted on (RSI) have highlighted, among others, (...) psychological factors, such as fatigue, higher levels of stress and loss of motivation and concentration (Fantinuoli, 2018; Moser-Mercer, 2011). Some of the most recent studies and their most relevant results within the scope of this paper are summarized below.

DG SCIC interpreters who participated in the European Parliament's test of four interpreting platforms in April and May 2019 correlated the high number of errors and issues to a lack of training on platform use before becoming familiar with its layout. Interpreters noted that "getting accustomed to the new tools would certainly decrease stress and fatigue" (European Commission, 2019).

In a survey conducted to 66 interpreting students from the University of International Studies in Rome during April 2019, interpreters complain about the lack of training in RSI and highlight the familiarity with the RSI platform as an essential factor to boost performance (Saina, 2021). There was no mention to stress or fatigue, however it is important to note that interpreting students were co-located in an interpreting hub and supported by a team of technicians.

A survey conducted in 2020 to 27 conference interpreters in Turkey aimed at exploring trends in the perception of remote interpreting revealed that the majority of the interpreters interviewed were comfortable with troubleshooting with internet connection however they were largely undecided when asked about their ability to handle connection problems or other technical problems during an assignment, in line with their claim of not being very knowledgeable in computer hardware and peripherals (Kincal \& Ekici, 2020).

A research project on RSI conducted by two researchers at the École supérieure d'interprètes et de traducteurs (ESIT) to 946 professional interpreters between March and April 2021, revealed that 50\% of the 857 eligible respondents believe that their performance is worse, compared to on-site interpreting, while $83 \%$ consider that RSI is more difficult (Collard \& Bujan, 2021).

In a survey conducted by the Canadian Association of Professional Employees to $73^{1}$ professional interpreters registered with the Association 93\% have interrupted the interpretation during an ongoing assignment because of poor sound quality, nearly half of which (43\%) resumed even if the sound quality issue was not resolved. $87 \%$ of

Responses were gathered from 43 participants 
respondents experienced high or very high levels of stress (Canadian Association of Professional Employees, 2021).

An article produced by an AIIC interpreter and voice researcher claimed that, compared to the sound produced in traditional conferencing audiovisual systems, the sound delivered by RSI and videoconferencing platforms is of poor quality due to its frequency range being limited to no more than one third of the audible spectrum and noise suppression, feedback cancelling and other algorithms. The author argues that high and very high frequency information, crucial to understanding speech in complex acoustic environments, is suppressed, resulting in overworking of the interpreter's ears and nervous system (Caniato, 2020).

In a focus group conducted by the author with four practicing interpreters in June 2021, the items identified as important factors which make RSI more difficult than inperson interpreting were technical accountability as interpreters are responsible for their own equipment, poor incoming audio and not being co-located to their boothmate.

\section{Stress, performance, and control}

While none of the recent studies have included a clinical approach in their evaluation of stress and performance during RSI, many of the early studies did indeed focus not only on self-perception but also on medical and physiological examination to determine changes in stress levels as well as independent expert evaluation to measure performance.

Early and recent studies alike resulted in a generally negative and more stressful perception of remote interpreting when compared to in-person interpreting, however studies which included a clinical approach did not find significant changes in stress hormone values nor increases in stress level were observed. With regards to quality, independent reviews found that performance was not negatively affected by RSI despite a generally negative self-perception of performance from the interpreters themselves (European Parliament, 2002; Moser-Mercer, 2003; Roziner \& Shlesinger, 2010; Seeber \& AIIC, 2018; Fantinuoli, 2019)

Such results and a lack of correlation between RI/RSI and physiological changes lead researchers to assume that the underlying cause of a negative perception is lack of control of the situation during a RI/RSI assignment (Moser-Mercer, 2003; MoserMercer, 2005; Mouzourakis, 2006; Roziner \& Shlesinger, 2010; Ziegler \& Gigliobianco, 2018).

Control is much associated with the ability to anticipate, predict and respond to the unknown and is a known construct to ameliorate stress responses (Steptoe \& Poole, 2016) as well as increased optimism which subsequently resulted in active coping (Fontaine, Manstead, \& Wagner, 1993). In their review of the concept of psychological stress and in the most relevant literature, in an attempt to find a correlation with RI/RSI, Ricardi et al. note that "uncontrollable or unpredictable events are more stressful than controllable or predictable ones". The authors also identify the concept 
of "perception of the consequences of failure" as a relevant factor in psychological stress levels (Ricardi, Marinuzzi, \& Zecchin, 1998).

It can be assumed, therefore, that actions aimed at increasing control over unpredictable situations that arise during RSI (including, but not limited to, issues with sound, network failure, unscheduled software updates) as well as the unknown associated with the use of technology, in terms of software (including, but not limited to sound control applications, videoconferencing software), hardware (including, but not limited to, peripherals such as headsets, microphones, adapters, cables) and RSI platforms (multiple platforms have their own particular functions, dynamics and interfaces) will increase the interpreters' ability to anticipate, predict and respond to the unknown and therefore will improve their self-perceived stress and performance levels.

\section{Proposal for action}

In order to define, address and manage unpredictable situations in RSI I propose applying the Project Management Institute (PMI)'s approach to Risk Management as it is consistent with most modern risk management standards (Weaver, 2008; Mulcahy, 2003). Risk is defined by the PMI as "an uncertain event or condition, that if it occurs, has a positive or negative effect on a project's objective" (Project Management Institute, 2017) and is managed following six processes ${ }^{2}$. In Project Management, risk management is aimed at systematically and proactively addressing unknown and unpredictable situations in order to take control of the project (Mulcahy, 2003).

I propose that interpreters apply this approach to manage risks following the six standard processes, with the addition of a seventh process which is aimed at increasing even further the level of control of the risk ${ }^{3}$. By performing the 7-process approach to risk management, interpreters can identify those situations which are most likely to occur, plan an appropriate response and be better prepared if the risk occurs,

For a comprehensive analysis of Risk Management please see Mulcahy (2003).

3 This assumption is made on the basis of the author's experience as a telephone interpreting Training and Quality Manager for the Spanish LSP Interpret Solutions between 2008 and 2016, where interpreters were subject to unpredictable situations during their onboarding training process. Part of the onboarding process was a series of role-plays where the trainers introduced stress-inducing elements such as background noise, interruption in the call or bad speaker attitude, all of which were moderately frequent occurrences during telephone interpretation calls. When faced with similar situations in real calls, monitored as part of the quality management process of the company, interpreters that had been onboarded using this methodology were able to effectively manage the situation, proved to be resourceful and kept calm. The same role-plays were used as part of telephone interpreting training modules taught at several universities in Spain with significant differences in performance, self-perceived and observed stress and general attitude toward telephone interpreting. While a study was not performed at the time to determine correlation it can be assumed that interpreters who had been subject to unpredictable situations during their onboarding would show an overall better response when they occurred in real calls as opposed to interpreters who had not. 
therefore likely experiencing lower levels of psychological stress and drops in performance in the event of a risk taking place.

The six processes as well as the additional seventh process are detailed below and include RSI-specific examples for illustration purposes.

1. Plan Risk Management. Actions include determining categories of risk, analyzing lessons learned (i.e. issues that occurred in past RSI assignments) or determining which stakeholders to involve in risk management (i.e., other interpreters, family members, technical support from the preferred RSI platform who can help identifying risks)

2. Identify Risks. This is the most important process in this approach as it is aimed at recording as many risks as possible, appropriately categorize them, and, where applicable, identify triggers or early warning signs. There are several methods to identify risks such as using a prompt list of standard categories (i.e., network, sound, computer software, RSI platform, personal, environment), cause and effect diagrams, root cause analysis, or interviewing or brainstorming with stakeholders determined in the previous process. Risks are more effectively identified if they clearly state their effect (i.e. the risk of a glass of water spilling over the keyboard will have the effect of damaging the computer during an ongoing RSI assignment). A useful tool for documenting risk is an electronic risk register using a simple spreadsheet software, as illustrated in the sample below:

Table 1. Sample Risk Register

\begin{tabular}{|l|l|l|l|l|l|l|}
\hline ID & Category & Risk & Effect & Trigger & Probability & Impact \\
\hline & & & & & & \\
\hline & & & & & & \\
\hline
\end{tabular}

3. Perform Qualitative Risk Analysis. During this process, each risk is evaluated for its probability to occur and impact on the situation by allocating a subjective numerical probability and impact score, such as 1 to 5 or 1 to 10,1 being the lowest impact and probability and 5 or 10 the highest. Scoring risks will help identifying the top priority risks that need especial attention, i.e. those with the highest probability of occurring and the highest impact such as a dog barking loudly or a power outage due to temporary construction works in the building.

4. Perform Quantitative Risk Analysis. This process involves assigning objective values to those risks that allow it, by determining their probability in terms of percentage and their impact in terms of monetary value. For example, one interpreter has identified the probability of headset failure as $2 \%$ based on the issues occurred in assignments during the past three months and assigned the monetary value of the impact at $175 €$ which is the cost of purchasing an additional headset to use in case of failure. Many risks cannot have a monetary value added nor can their probability 
of occurring be measured precisely, therefore this process is very likely to be applicable to a few risks. Nevertheless, Quantitative Risk Analysis can also be a useful exercise to forecast possible costs and help budgeting, especially after adding up the monetary values of all quantified risks.

5. Plan Risk Response. The goal of this process is to determine actions to reduce the probability and impact of a negative risk and increase the likelihood of a positive risk. In the case of threats, are four response strategies: avoid (eliminate the cause), mitigate (reduce the probability or impact), transfer (assign the risk to someone else, typically by subcontracting an action or buying insurance) or accept (do nothing). The accept strategy is usually allocated to risks that cannot be avoided, transferred or mitigated, such as a natural disaster leading to a power outage. It is important to identify such risks as they can elicit contingency plans (i.e. switch to a battery operated device such as a mobile phone or tablet). In the case of opportunities, or risks with a positive outcome, the four strategies are embrace, enhance, share or accept. For example, outsourcing administrative and invoicing tasks to an accountant would be a sharing response to the opportunity of freeing up time spent on such tasks.

6. Monitor Risks. Once risks are identified and responses are planned, it is important to review the risk register and the planned responses regularly as new situations may lead to new risks or temporary situations have ceased to occur. Personal changes might even lead to including a brand-new category of risks, such as adopting a pet.

7. Practice Risk Response. This process focuses on live testing and practicing the risk response, especially to high probability, high impact risks, insofar as the risk identified allows it, in order to increase familiarity with the risk response and better coping with its application it in real-life situations. For example, one interpreter has identified interruption in the broadband internet connection as a high probability and high impact risk due to some temporary roadworks on her street. Her planned response is sharing the mobile data from her mobile phone and having the phone at hand in case an immediate switch to the phone's connection is needed. By practicing the risk response, she can actually test this situation by performing RSI on a practice platform or speech repository engine and turn off the broadband router at any given moment or, even better, asking a family member to turn off the broadband unexpectedly. This will not only automate the risk response and increase familiarity with the risk but may very likely lead to identifying secondary risks associated to the response which were missed during the planning process, such as having the phone connected to a power source, turning on the do-not-disturb mode to prevent interruptions or ensuring the phone's data plan supports high traffic.

Because risks arise from a varied set of circumstances which are unique to each interpreter's equipment, location, experience with the use of technology and personal circumstances among many other factors, it is important that the 7-process approach is performed individually by each interpreter for the best outcome. An interpreter who is tech-savvy, has three pets and works in an open-plan apartment will have identified 
different risks from an interpreter who is not familiar with technology, has small children and works from a home office which is independent from the rest of the house.

While the PMI's approach to Risk Management is an industry recognized methodology to reduce unknowns and regain control on projects across any industry or field of specialization and has several associated certifications that are globally recognized, further research to measure self-perceived stress and quality upon the application of the 7-process approach to remote interpreters is encouraged, the results of which would be of great value to an increasingly demanded profession.

\section{References}

1. AIIC Taskforce on Distance Interpreting, https://aiic.org/site/TFD0, last accessed 2020/06/03.

2. Braun, S.: Remote interpreting. In Mikkelson, H., Jourdenais, R. (eds) The Routledge Handbook of Interpreting, pp. 352-367. Routledge (2015).

3. Canadian Association of Professional Employees: Survey of Interpreters Experience with Virtual Sittings of Parliament. Ottawa, Ontario: ACEP-CAPE (2021).

4. Caniato, A: The Proposed Pathodynamics of the Junk Sound Syndrome: Why RSI sound is bad for the interpreter's ears (2020, July 14). Retrieved June 2021, from LinkedIn: https://www.linkedin.com/pulse/proposed-pathodynamics-junk-sound-syndrome-why-rsibad-andrea-caniato/

5. Collard, C., \& Bujan, M.: Research Project on Remote Simultaneous Interpreting. Paris: ESIT (2021).

6. Congress Rental Australia: The state of Remote Simultaneous Interpretation in 2020-21: an insight into the remote simultaneous interpretation experience for interpreters and how it can be improved. Sidney: Congress Rental Network (2021).

7. Dörte, A., Falk, S.: Download Information and Communication Technologies (ICT) in Interpreting Remote and Telephone Interpreting. Spürst Du wie der Bauch rauf-runter? Fachdolmetschen im Gesundheitsbereich (InterPartes), 9-27 (2009).

8. Dranch, K.: Report for Conference Interpreting after Covid-19 . Prague (2021).

9. European Commission: Interpreting Platforms Consolidated test results and analysis. Brussels: European Commission DG Interpretation (2019).

10. European Parliament: Report on the 2nd EP Remote Interpretation Test. European Parliament, Working Party on New Technologies of the Interpretation Directorate, Brussels (2002).

11. Fantinuoli, C.: Interpreting and technology: The upcoming technological turn. Interpreting and technology, 1-12 (2018).

12. Fantinuoli, C.: The Technological Turn in Interpreting: The Challenges That Lie Ahead. In: BDÜ Conference Translating and Interpreting 4.0, Bonn (2019).

13. Fontaine, K., Manstead, A., Wagner, H.: Optimism, perceived control over stress, and coping. European Journal of Personality 7(4), 267-281 (1993).

14. Gile, D.: Basic Concepts and Models for Interpreter and Translator Training. John Benhamins, Amsterdam/Philadelphia (2009).

15. International Organization for Standardization: ISO/PAS 24019 Simultaneous interpreting delivery platforms - Requirements and recommendations (2019). Retrieved June 2020, from https://www.iso.org 
16. Jimenez Serrano, O.: Foto fija de la interpretación simultánea remota al inicio del 2020. Revista Tradumática. Tecnologies de la Traducció 17, 59-80 (2019).

17. Kincal, Ş., Ekici, E.: Reception of remote interpreting in Turkey: A pilot study. RumeliDE Dil ve Edebiyat Araştırmaları Dergisi 21, 979-990 (2020).

18. Moser-Mercer, B.: Remote interpreting: Assessment of human factors and performance parameters. Joint project International (2003).

19. Moser-Mercer, B.: Remote Interpreting: Issues of Multi-Sensory Integration in a Multilingual Task. Meta 50(2), 727-738 (2005).

20. Moser-Mercer, B.: Remote interpreting. In: Gambier, Y., Van Doorslaer, L. (eds.) Handbook of Translation Studies, vol. 2. John Benjamins Publishing Company, Amsterdam/ Philadelphia (2011).

21. Mouzourakis, P.: Remote interpreting A technical perspective on recent experiments. Interpreting 8(1), 45-66 (2006).

22. Mulcahy, R.: Risk Management, Tricks of the Trade for Project Managers. RMC Publications, United States of America (2003).

23. Project Management Institute: A guide to the Project Management Body of Knowledge (PMBOK guide). Project Management Institute, Pennsylvania (2017).

24. Ricardi, A., Marinuzzi, G., Zecchin, S.: Interpretation and Stress. The Interpreters' Newsletter 8, 93-106 (1998).

25. Roziner, I., Shlesinger, M. Much ado about something remote: Stress and performance in remote interpreting. International Journal of Research and Practice in Interpreting 12(2), 214-247 (2010).

26. Saina, F. Remote Interpreting: Platform Testing in a University Setting to Shape a PostCOVID Scenario. In: ITA 2021 Conference: The new Workd - Translation in an Age of Uncertainty. Israel Translators Association, Tel Aviv (2021).

27. Seeber, K., \& AIIC.: Interpreting from the sidelines: Attitudes towards remote interpreting at the 2014 FIFA World Cup. University of Geneva, Faculty of Translation and Interpreting, Geneva (2018).

28. Steptoe, A., Poole, L.: Control and Stress. In: Fink, G., Editor, Stress: Concepts, Cognition, Emotion, and Behavior. Academic Press, London (2016).

29. United Nations: A joint experiment in remote interpretation. UNHQ-UNOG-UNOV. Geneva: United Nations, Department of General Assembly Affairs and Conference Services (1999).

30. Ünlü, C.: Remote Simultaneous Interpretation in Pre and Post- COVID-19: An Overview of the Profession Revisited from Sectoral, Ethical, and Pedagogical Perspectives. Interdisciplinary Debates on Discourse, Meaning and Translation, 311-337 (2021).

31. Weaver, P.: The meaning of risk in an uncertain world. In: PMI Global Congress 2008. Malta (2008).

32. Ziegler, K.: Gigliobianco, S. Present? Remote? Remotely present! New technological approaches to remote simultaneous conference interpreting. In: Fantinuoli, C., Editor, Interpreting and technology, pp. 119-139. Language Science Press, Berlin (2018). 